\title{
Performance and Evaluation of Ohmic Heating Assisted Lye and Salt Concentration on Peeling Quality of Tomato
}

\author{
S.R. Sawant ${ }^{1 *}$, J.P. Pandey ${ }^{2}$, Anupama Singh ${ }^{2}$ and Om Prakash ${ }^{3}$ \\ ${ }^{1}$ Division of Agricultural Engineering, IARI, New Delhi, India \\ ${ }^{2}$ Department of Post-Harvest Process and Food Engineering, GBPUAT, \\ Pantnagar (UK), India \\ ${ }^{4}$ Department of Chemistry, GBPUAT, Pantnagar (UK), India \\ *Corresponding author
}

\section{Keywords \\ Ohmic heating, Lye and salt concentrations, Field strength, Peeling \\ Article Info \\ Accepted: \\ 24 August 2018 \\ Available Online: \\ 10 September 2018}

\section{A B S T R A C T}

The peeling qualities of tomato by using ohmic heating assisted lye-salt concentrations were investigated. The principle of ohmic heating is dissipation of electrical energy into heat which results in internal energy generation. The other methods of peeling are possess various disadvantages which include use of caustic, high $\mathrm{pH}$, problem of waste disposal, high pressure and energy and excessive use of water with the latter. In this study, ohmic peeling was attempted to potentially address these problems. The peeling performance of final product was evaluated in terms of time of skin cracking, percentage of peeling and ease of peeling. When the lye- salt concentration of the medium increased, the heat generation in the medium would be quicker due to higher electrical conductivity. The wax melting would accelerate, resulting in low process time. In terms of time of cracking, the best performance of ohmic treatment was obtained at $0.3 \% \mathrm{NaOH}$ concentration at 1214.28 V/m. The condition showed the probable to be good for processing because they required a relatively short time (less than $60 \mathrm{~s}$, approximately). Moreover, the potential to preheat the media to $60{ }^{\circ} \mathrm{C}$ with reusable media could further shorten the peeling time. Ohmic tomato peeling treatments with $\mathrm{NaOH}(0.1,0.20 .3$ and $0.4 \%)$ were better than those by ohmic heating with either $\mathrm{NaCl}$ or $\mathrm{KOH}$, in terms of quality of peeling.

\section{Introduction}

Ohmic heating is also termed as 'resistance heating or electro heating' in which an alternating electric current is passed through a food, and electric resistance of the food causes the power to be translated directly into heat.

The principle of ohmic heating is dissipation of electrical energy into heat which results in internal energy generation (Eliot et al., 1991). The food product is heated rapidly as the rate of heating is only relevant to the electrical resistance of the particular food and not limited by the heat transfer coefficient.

Additionally, there is no limitation regarding the penetration depth as exhibited in dielectric heating technologies such as microwave and IR (Fellows, 2000). 
During tomato products manufacture the peel fraction of tomatoes could be used as a value additional ingredient in other food products where it could play a significant role in improving antioxidant intake in the human diet (Dareo, 2009). Due to tomato peel content of various nutrients and its antioxidant activities, tomato peel or its extracts can be used as a food supplement. The plenty of bioactive compounds in by-products suggests possibility of utilizing them as an economical source of different bioactive compounds and high value functional.

The mechanism of peeling appears to be a complex combination of chemical, thermal electrical and physical effects (Floros et al., 1987). Processing tomatoes are peeled by chemical lye peeling (using $\mathrm{NaOH}$ and $\mathrm{KOH}$ ), steam hot water, salt solution etc. Improper lye peeling caused over peeling problem. In which many layers of tomato flesh are removed resulting in an undesirable light red color and exposure of some superficial yellowish layers (Cheryl et al., 2012).

The water within the tomato flesh (pericarp) vaporizes causing an internal pressure to build up under the skin leading to its rupture, facilitate the separation of the epicarp from the pericarp. During lye peeling a solution of sodium hydroxide and potassium hydroxide comes into contact with fruit and diffuses into the epidermal and hypodermal cells of the fruit, where several chemical reactions take place ( $\mathrm{Li}$ et al., 2009). In tomato processing industry the most commonly employed methods at present are the steam and lye (Fellows, 2000 and Garcia, 2005). Both of them possess disadvantages which include use of caustic, high $\mathrm{pH}$, problem of waste disposal, high pressure and energy and excessive use of water. Spent lye is subjected as an environmental pollutant (Cheryl et al., 2012). Lye peeling technique is putting both environmental and economical pressure on tomato processing industry, due to salinity and wastewater disposal problems ( $\mathrm{Li}$ et al., 2009). The limitations of above peeling methods in particular have demanded the urgency and need for optional and sustainable "eco-friendly" technologies in the tomato processing industry (Cheryl et al., 2012). To overcome these problems several researcher workers, (Fellow 2000 and Cheryl et al., 2012) have investigated other alternative novel techniques for removal of tomato skin.

Therefore this study will deal with the effect of ohmic heating, salt and lye solutions on peeling quality of tomato. To improve the lye peeling and minimize the environmental impact, ohmic heat treatment might be a viable and unique method for tomato peeling with lye solution. Keeping all above cited issue in mind, the present work has been undertaken with the objective to study the effect ohmic heating assisted of lye and salt concentrations on peeling quality of tomato.

\section{Materials and Methods}

During the experiments the peeling quality characteristics (time of skin cracking, percentage of peeling and ease of peeling) of tomato were evaluated. Applied field strength, salt levels and lye levels were taken as independent variables for the study and their ranges were finalized based on the observations and results obtained in preliminary experiments.

\section{Experimental location}

The Experiments were conducted in the laboratory of Department of Post-Harvest Process and Food Engineering, College of Technology and the laboratory of Department of Chemistry, College of Basic Sciences and Humanities, G.B. Pant University of Agriculture and Technology, Pantnagar, Uttarakhand, India. 


\section{Raw materials}

Fresh, fully matured, red in colored cherry type tomatoes of variety Pant Bahar was selected as the raw material for ohmic heating. The tomatoes were washed in clean water to remove dust or other foreign materials on it and then wiped with cotton cloth.

\section{Experimental plan}

Certain constant parameters were fixed for entire experiments, decided on the basis of trial runs. The Conclusive lists of these parameters are number of tomato (one), Variety of tomato (Pant Bahar) and Weight of sample (60 gm App). Standard ohmic heating variables consisting of salt concentration, lye concentrations and field strength were selected. The levels of the variables have been chosen based on preliminary runs and literature reviewed.

The levels and values of each of these variables are $4,4,4$ and $0.1 \%, 0.2 \%, 0.3 \%$ and $0.4 \%$ respectively. The applied field strength levels and values are 3 and $1214.28 \mathrm{~V} / \mathrm{m}$, $1071.42 \mathrm{~V} / \mathrm{m}$ and $928.57 \mathrm{~V} / \mathrm{m}$ respectively. Full factorial design was selected for the present study. Responses of the independent variables are time of skin cracking, percentage of peeling and ease of peeling.

\section{Preparation of salt and lye concentrations solution}

Salt and lye concentrations were prepared on the basis of weight / volume percentage. For $0.1 \%$ of salt concentration dissolved $0.1 \mathrm{~g}$ of salt in $100 \mathrm{ml}$ of distilled water similarly for $0.2 \%, 0.3 \%$ and $0.4 \%$ dissolved $0.2 \mathrm{~g}, 0.3 \mathrm{~g}$ and $0.4 \mathrm{~g}$ of salt in $100 \mathrm{ml}$ of distilled water respectively. For $0.1,0.2,0.3$ and $0.4 \%$ of Lye concentrations $(\mathrm{NaOH}$ and $\mathrm{KOH})$ dissolved 0.1, 0.2, 0.3 and $0.4 \mathrm{~g}$ of lye powder in $100 \mathrm{ml}$ of distilled water respectively.

\section{Experimental methodology}

\section{Experimental setup}

As shown in plate.2.1 the ohmic heating setup was to carry out the experiments was designed and fabricated by Kautkar et al., (2016). The ohmic heating chamber is very important for efficient heating employed a circular geometry was constructed by PVC pipes of $7 \mathrm{~cm}$ diameter, $16.8 \mathrm{~cm}$ in length and $2 \mathrm{~mm}$ in thickness. The electrodes have well grade, non-corrosive and chemically inert made from stainless steel (SS) with $5.5 \mathrm{~cm}$ diameter. The distance between two electrodes has kept 14 $\mathrm{cm}$ to pass maximum voltage gradient of 16.5 $\mathrm{V} / \mathrm{cm}$ from Indian household electric supply of $230 \mathrm{~V}$. Bestronics made digital temperature controller with stainless steel probe was used monitor the temperature inside the heating chamber. Teflon coated, J type thermocouple which can withstand a temperature of $0-600^{\circ}$ $\mathrm{C}$ is placed at the geometric centre of the ohmic heating cylinder to control the temperature during ohmic heating. A base is used to fix entire ohmic setup and control panel.

\section{Experimental procedure}

Initially single tomato weighted by using electronic weighing balance meter. The solutions which were used as medium in ohmic heating device for tomato peeling was prepared on the basis of weight per volume percentage concentration. The prepared solution was poured into ohmic heating chamber and preheated without tomato up to $65^{\circ} \mathrm{C}$ temperatures was reached. Thereafter, the tomato was immersed in ohmic heating chamber, and ohmic treatment was applied unit till crack was observed on tomato surface. The temperature, cracking time and flowing current was measured at similar time. If any case the current became zero and did not show any increase, the experiment was terminated. 
The A.C power was turned off once tomato cracked. The prepared tomato was cooled at room temperature and then transferred to calculate percentage of peeling on the weight loss basis and ease of peeling.

\section{Analytical techniques for quality parameter}

\section{Percentage of peeling}

Peel quality was assessed subjectively and recorded after every experiment. The percentage of peeling was determined in terms of weight loss and expressed as percentage. The weight loss observed from how much the tomato flesh detached from the fruit. The ratio of initial weight of tomato to the final weight after removal of peel defines percentage of peeling weight losses of tomato as influenced by different postharvest treatments were estimated using the following formula:

Weight Loss $(\mathrm{WL})=\frac{\frac{W 1-W 2}{W 2}}{W 10}$

$\mathrm{WL}=$ Percentage of peeling, $\%$

$\mathrm{W} 1=$ Initial weight of tomato before peeling, $\mathrm{g}$

$\mathrm{W} 2=$ Final weight of tomato after peeling, $\mathrm{g}$

\section{Ease of peeling}

The ease of peeling was evaluated subjectively by a method developed by Li et al., (2009), using descriptors with a qualitative grade scale ranging from 1 (difficult to peel) to 5 (easy to peel) as shown in below Table 1. This method was performed using manual peeling calibrated by training subjects to peel untreated tomatoes versus treated tomatoes.

\section{Results and Discussion}

The experiments were planned keeping field strengths, lye $(\mathrm{NaOH}$ and $\mathrm{KOH})$ and salt
$(\mathrm{NaCl})$ concentrations as the independent parameters. The influence of various factors were analyzed using a statistical technique i.e. Analysis of Variance (ANOVA) by SAS (Statistical Analysis System) version 9.1. The significance of any factor was judged by comparing the corresponding $\mathrm{F}_{\mathrm{cal}}$-value in the ANOVA $\left(F_{\mathrm{ca}} \mathrm{l}\right)$ table with $\mathrm{F}_{\mathrm{tab}}$-value. The result obtained in this study are presented and discussed in the following sections:

\section{Effect of electric field strength and concentration (lye-salt) on time of cracking}

Figure 1, 2 and 3 shows interrelationship between concentrations of lye-salt solution and time of cracking at $1214.28 \mathrm{~V} / \mathrm{m}, 1071.42$ $\mathrm{V} / \mathrm{m}$ and $928.57 \mathrm{~V} / \mathrm{m}$ respectively. The important factors affect the tomato peeling are time of skin cracking, characteristics of the exocarp (consisting of the outer epidermis), cultivars, genetics, climate, seasonal variation and maturity (Went, 1994). The time required for cracking single tomato under different levels of electric field strength $(\mathrm{V} / \mathrm{m})$, lye concentrations $(\mathrm{NaOH}, \mathrm{KOH})$ and salt concentrations $(\mathrm{NaCl})$ were assessed and data obtained were analyzed.

Time required for cracking single tomato under different electric field strengths of $1214.28 \mathrm{~V} / \mathrm{m}, 1071.42 \mathrm{~V} / \mathrm{m}, 928.57 \mathrm{~V} / \mathrm{m}$ and $0.1 \%, 0.2 \%, 0.3 \%$ and $0.4 \%$ concentrations of $\mathrm{NaOH}$. Were recorded as $55.2 \mathrm{~s}$ and $27.1 \mathrm{~s}$ for $0.1 \% \mathrm{NaOH}(928.57 \mathrm{~V} / \mathrm{m})$ and $0.3 \% \mathrm{NaOH}$ $(1214.28 \mathrm{~V} / \mathrm{m})$ respectively. The data were tabulated as average of the 3 replicates \pm standard deviation (SD). Similarly time of cracking under various field strengths for $\mathrm{KOH}$ and $\mathrm{NaCl}$ concentrations was carried out. Least time of cracking (43.5 s) was observed for $0.3 \% \mathrm{KOH}$ at $1214.28 \mathrm{~V} / \mathrm{m}$ of field strength. The maximum time of cracking (113.2 s) was recorded for $0.1 \% \mathrm{KOH}$ at $928.57 \mathrm{~V} / \mathrm{m}$ field strength. When the electric field strength increases, the solution 
temperature would also increase as expected. The effects of field strength $(\mathrm{V} / \mathrm{m})$ and sodium chloride concentration $(0.1 \%-0.4 \%)$ showed that the time required for cracking single tomato varied from $109 \mathrm{~s}$ to $211.3 \mathrm{~s}$. Maximum time $(211.3 \mathrm{~s})$ resulted for tomato cracking was recorded for $0.1 \% \mathrm{NaCl}$ at 928.57 V/m field strength while minimum time (109 s) resulted for tomato cracking was recorded for $0.3 \% \mathrm{NaCl}$ at $1214.28 \mathrm{~V} / \mathrm{m}$ field strength. The heat generation in the medium would be quicker due to higher electrical conductivity. The wax melting would accelerate, resulting in low process time. Although cracking occurred faster at the higher electric field strength was found better than that reported by Cheryl et al., (2012).

Figures showed that maximum time of cracking for all concentrations were observed in salt $(\mathrm{NaCl})$ followed by potassium hydroxide $(\mathrm{KOH})$ and sodium hydroxide $(\mathrm{NaOH})$ for all experimental field strengths. Minimum reduction in time of cracking was observed at $0.3 \% \mathrm{NaOH}$ concentration at $1214.28 \mathrm{~V} / \mathrm{m}$ field strength.

The comparative results which were obtained from experimental data are shown in Figure 4. which showed that the minimum time of cracking observed under sodium hydroxide $(\mathrm{NaOH})$ concentration with high field strength and maximum time of cracking evaluated under salt concentration $(\mathrm{NaCl})$ low field strength. It also showed that increasing the concentrations of $\mathrm{NaOH}, \mathrm{KOH}$ and $\mathrm{NaCl}$ from $0.1 \%$ to $0.4 \%$ with field strengths $928.57 \mathrm{~V} / \mathrm{m}$ to $1214.28 \mathrm{~V} / \mathrm{m}$ shorter times required for skin cracking. The maximum time of cracking $(211.33 \mathrm{~s})$ occurred at $0.1 \% \mathrm{NaCl} / 928.57 \mathrm{~V} / \mathrm{m}$ field strength and the minimum time of cracking $(27.16 \mathrm{~s})$ occurred at $0.3 \% \mathrm{NaOH}$ and $1214.28 \mathrm{~V} / \mathrm{m}$ field strength.

Cracking of the tomato under various concentration $(\mathrm{NaOH}, \mathrm{KOH}$ and $\mathrm{NaCl})$ may be because of high temperature conditions in the peeling medium contribute to the formation of vapor under the tomato skin and due this increased internalized pressure the tomato skin results in its cracking. The physical changes exhibited are a combination of both biochemical and thermal effects, which enhance the bio-separation between the endocarp and pericarp resulting in the splitting of the skin.

\section{Effect of electric field strength and concentration (lye-salt) on percentage of peel and ease of peeling}

The graphical representation of percentage of peeling of tomato under different field strengths and concentrations of $\mathrm{NaOH}, \mathrm{KOH}$ and $\mathrm{NaCl}$ are presented in Figure 5, 6 and 7 respectively which were supported by the experimental data. The data were tabulated as average of the 3 replicates \pm standard deviation (SD). Parentage of peel and ease of peeling varied from 8.27 to 17.26 and 5 to 3 score grade for $0.3 \%(1214.28 \mathrm{~V} / \mathrm{m})$ and $0.2 \%$ $(928.57 \mathrm{~V} / \mathrm{m})$ concentrations of $\mathrm{NaOH}$ respectively.

The maximum percentage of peel (17.26) was found at $79.7^{\circ} \mathrm{C}$ whereas; at temperatures of $85.7^{\circ} \mathrm{C}$ minimum percentage of peel (8.27) was recorded shows that all the experimented samples having the ease of peeling in the range score, varied from low (3) to high value (5). The reported average ease of peeling scores for ohmic heated sample were 4, 4, 5, $5,5,3,4,3,4,3,5,5$ for $1214.28 \mathrm{~V} / \mathrm{m}$, $1071.42 \mathrm{~V} / \mathrm{m}$ and $928.57 \mathrm{~V} / \mathrm{m}$ for four concentrations. The best result were evaluated for the ease of peeling having out of score were $0.3 \% \quad(1214.28 \mathrm{~V} / \mathrm{m}), 0.4 \% \quad(1214.28$ $\mathrm{V} / \mathrm{m}), \quad 0.1 \% \quad(1071.42 \mathrm{~V} / \mathrm{m}), \quad 0.3 \% \quad(928.57$ $\mathrm{V} / \mathrm{m})$ and $0.4 \% \quad \mathrm{NaOH} \quad(928.57 \quad \mathrm{~V} / \mathrm{m})$ respectively. The percentage of peeling of tomato under various concentrations for $\mathrm{KOH}$ were Obtained from $13.19 \%$ to $25.79 \%$. 
Table.1 Descriptions used to evaluate the easiness of peel of cherry type tomatoes

\begin{tabular}{|c|c|}
\hline Scale & Subjective Descriptions for Ease of Peeling \\
\hline 1 & $\begin{array}{l}\text { Very difficult to remove peel; large amounts of residual skin on tomatoes and high loss } \\
\text { of flesh due to its adherence to the skin during peeling }\end{array}$ \\
\hline 2 & $\begin{array}{l}\text { Difficult to remove peel on most area s of the tomatoes; residual skin on certain areas of } \\
\text { the tomatoes }\end{array}$ \\
\hline 3 & Moderately difficult to remove peel; little residual skin on the surface of the tomatoes \\
\hline 4 & Easy to remove peel; large pieces of tomato peel can be removed with little effort \\
\hline 5 & Very easy to remove peel; no residual skin on the tomatoes \\
\hline
\end{tabular}

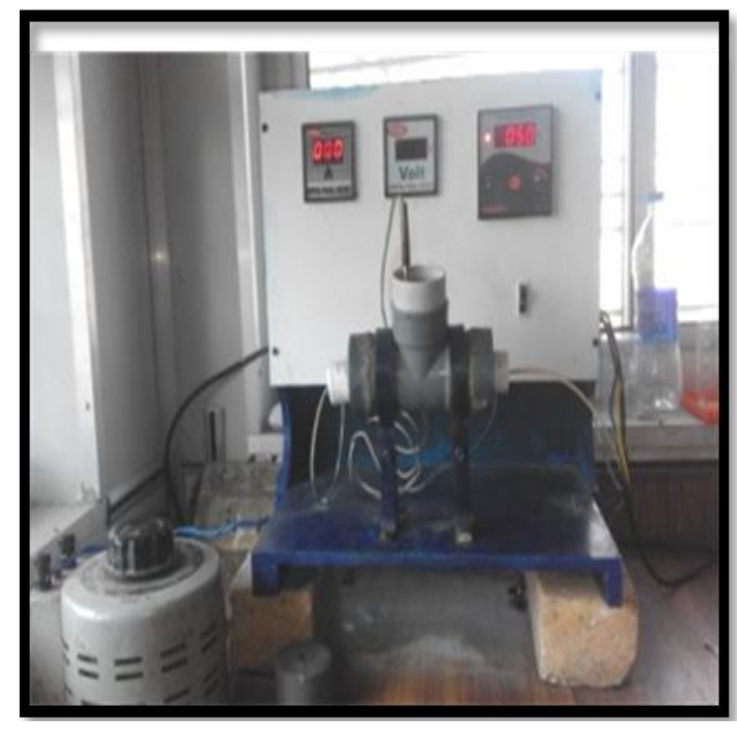

Plate 2.1 Ohmic heating setup

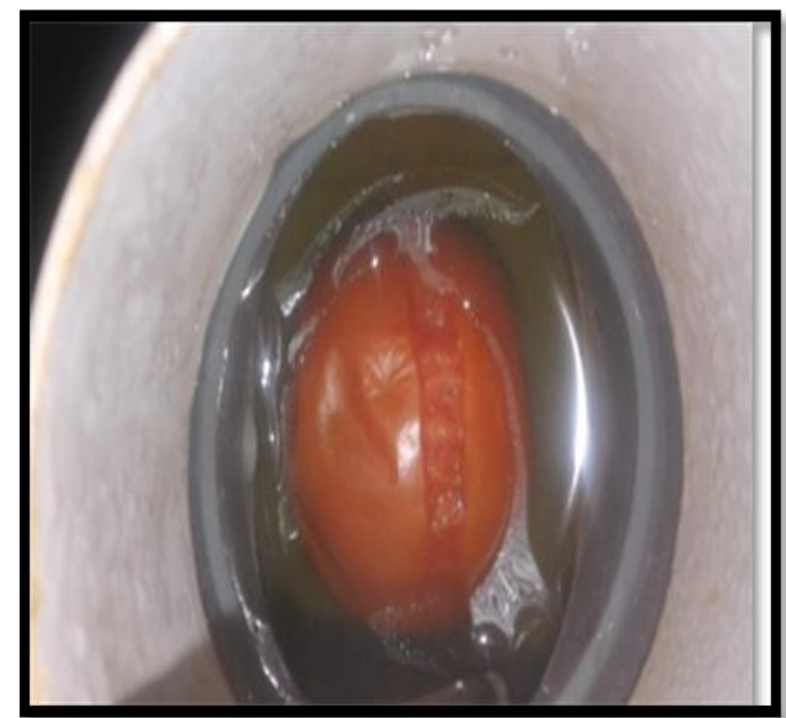

Plate 2.2 Cracking occurred during Ohmic heating

Fig.1 Interrelationship between concentrations and time of cracking at 1214.28 V/m

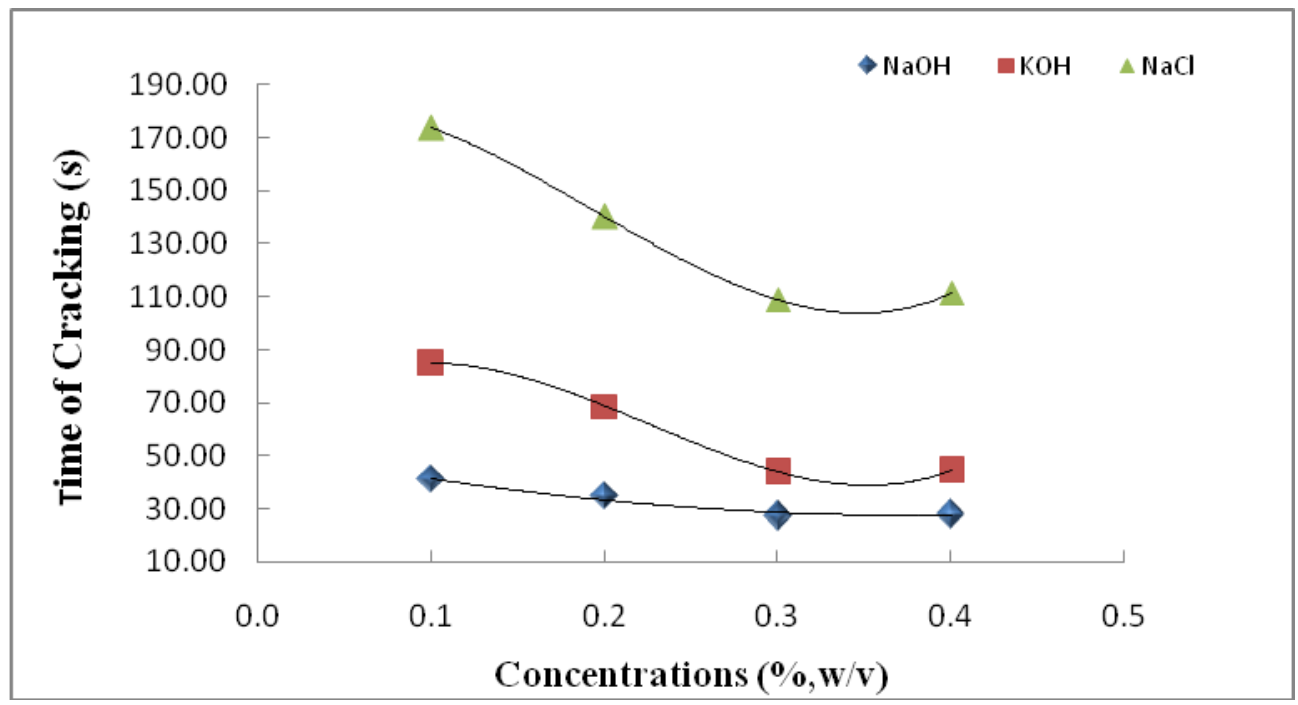


Fig.2 Interrelationship between concentrations and time of cracking at $1071.42 \mathrm{~V} / \mathrm{m}$

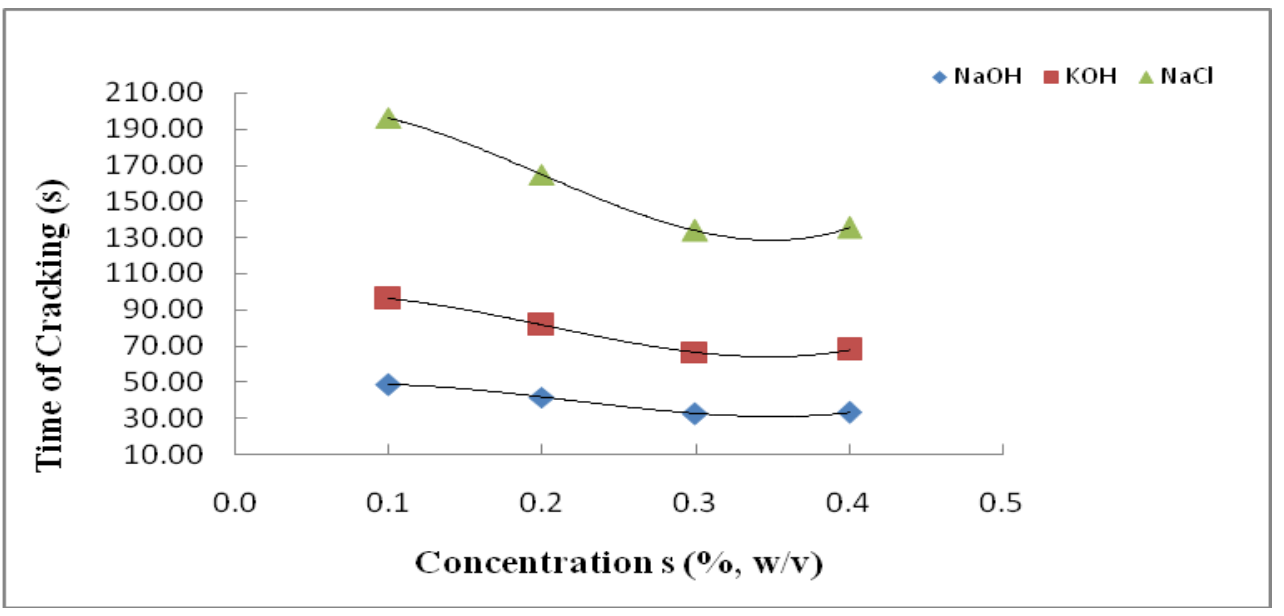

Fig.3 Interrelationship between concentrations and time of cracking at $928.57 \mathrm{~V} / \mathrm{m}$

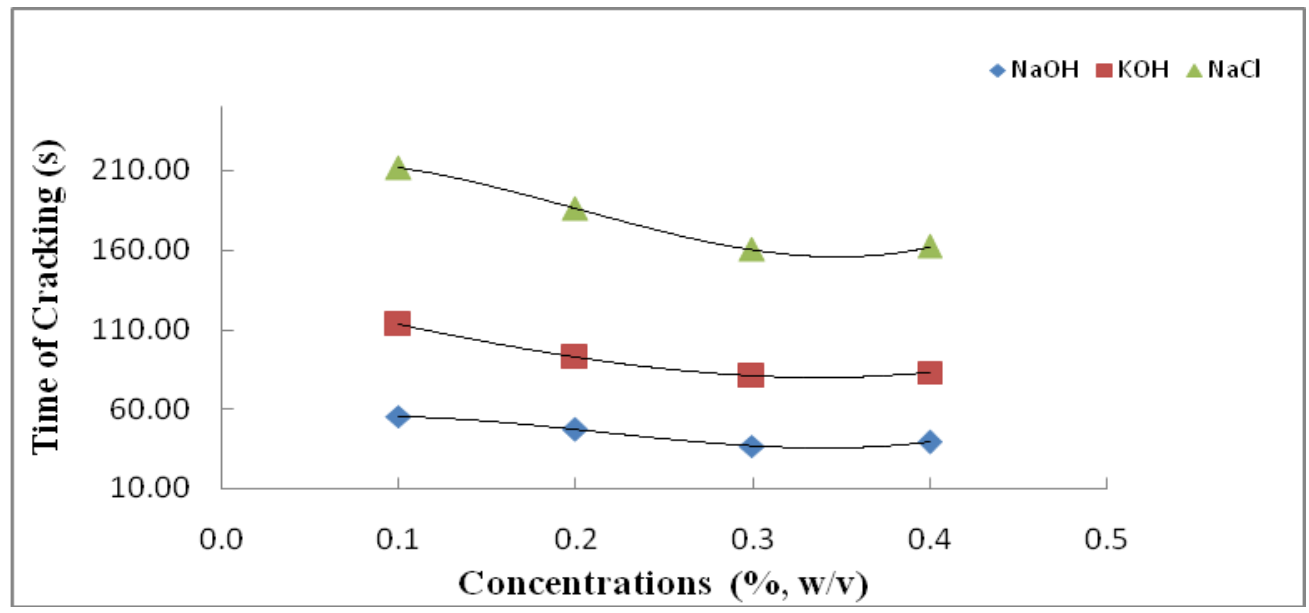

Fig.4 Comparison of time of cracking under various field strength and lye-salt concentration

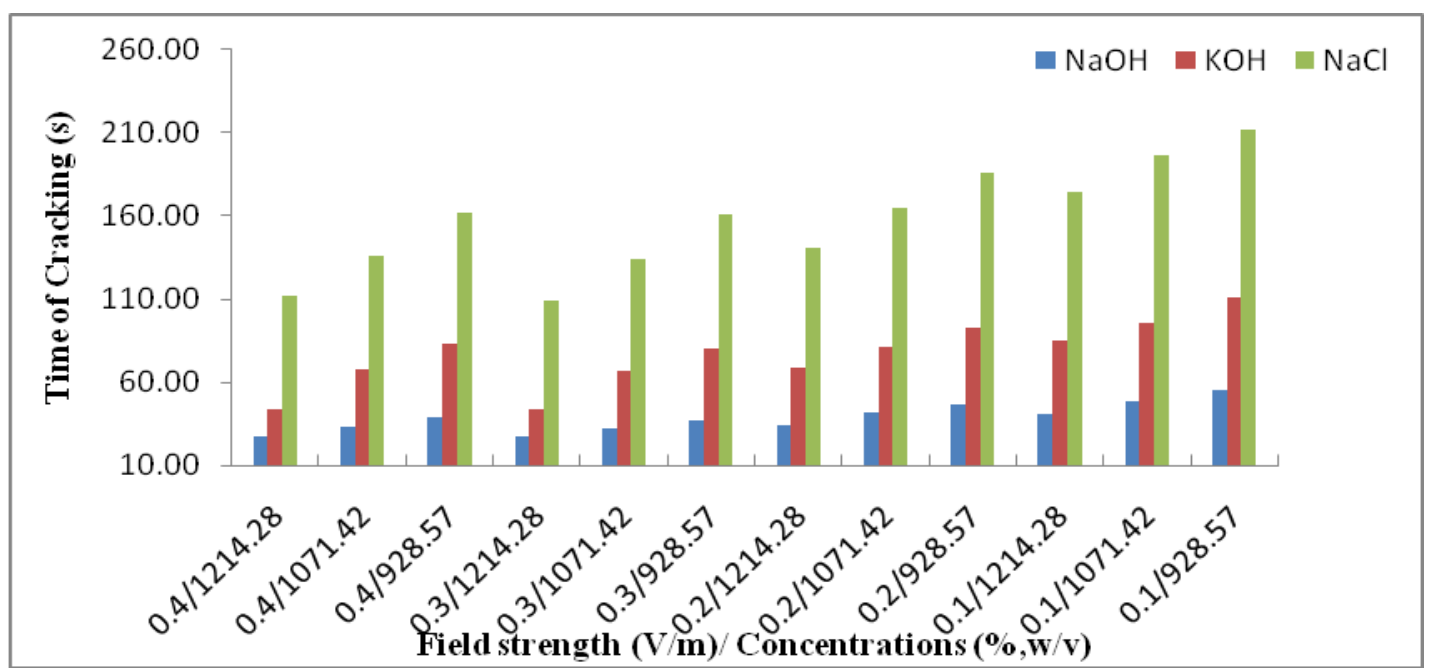


Fig.5 Percentage of peeling of tomato at $1214.28 \mathrm{~V} / \mathrm{m}$ and lye- salt concentration

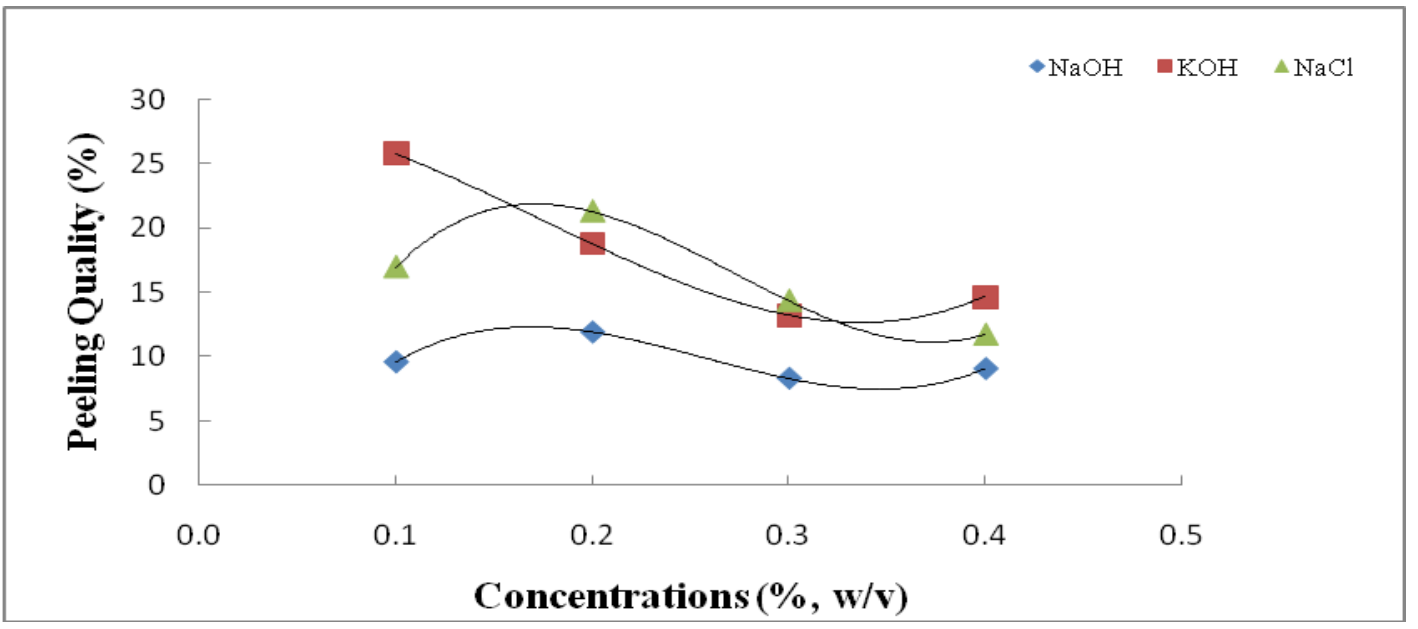

Fig.6 Percentage of peeling of tomato at $1071.42 \mathrm{~V} / \mathrm{m}$ and lye- salt concentration

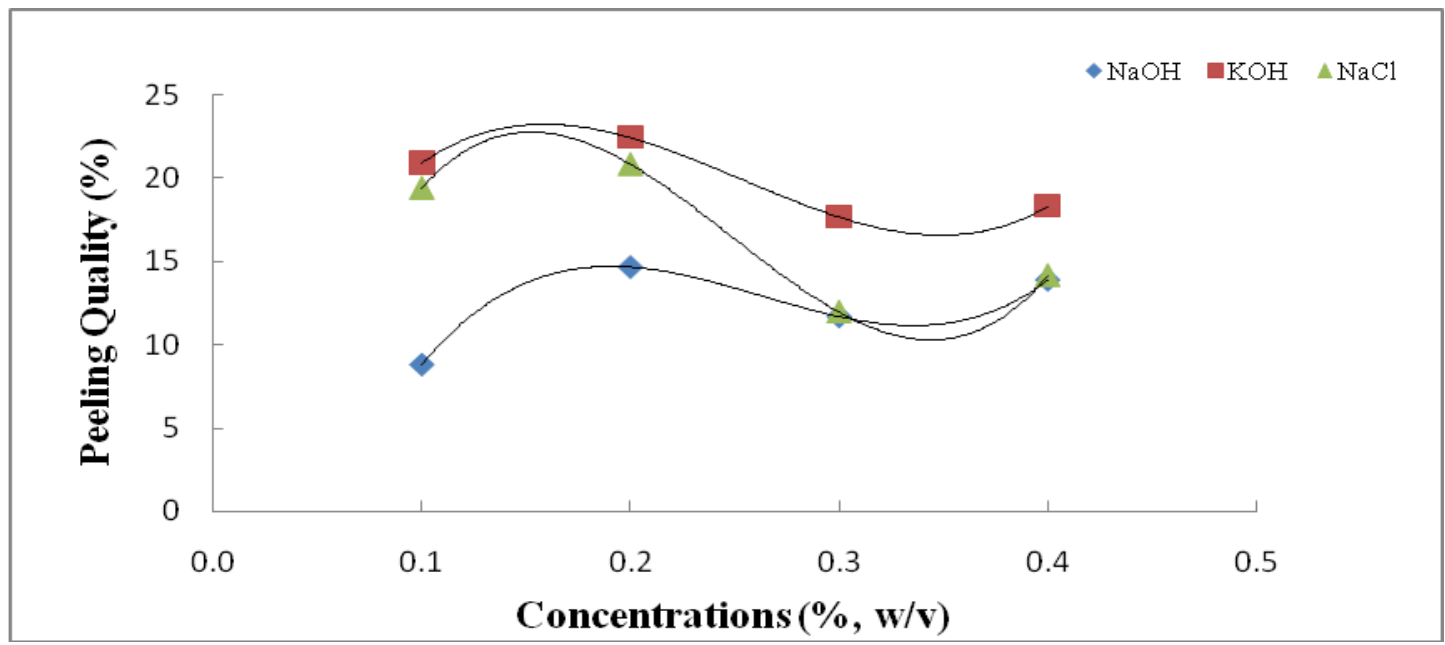

Fig.7 Percentage of peeling of tomato at $928.57 \mathrm{~V} / \mathrm{m}$ and lye- salt concentration

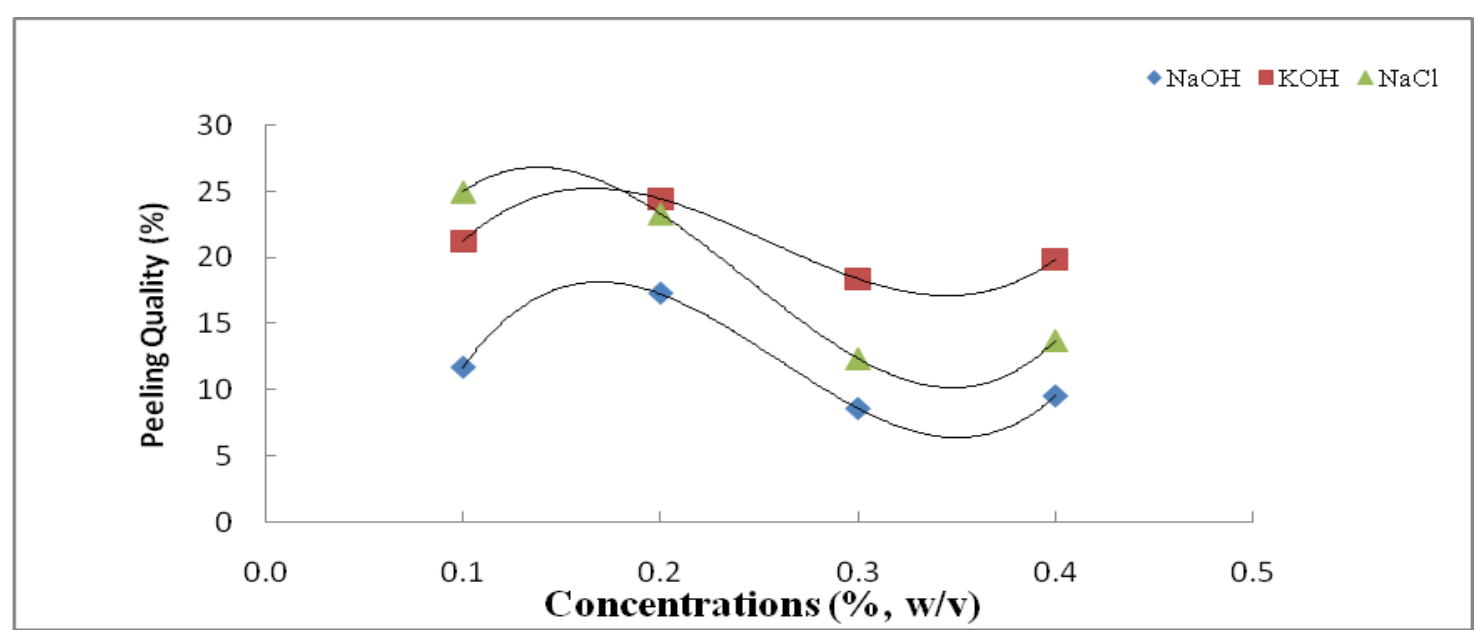


Fig.8 Comparison of percentage of peeling under various field strength and lye-salt concentration

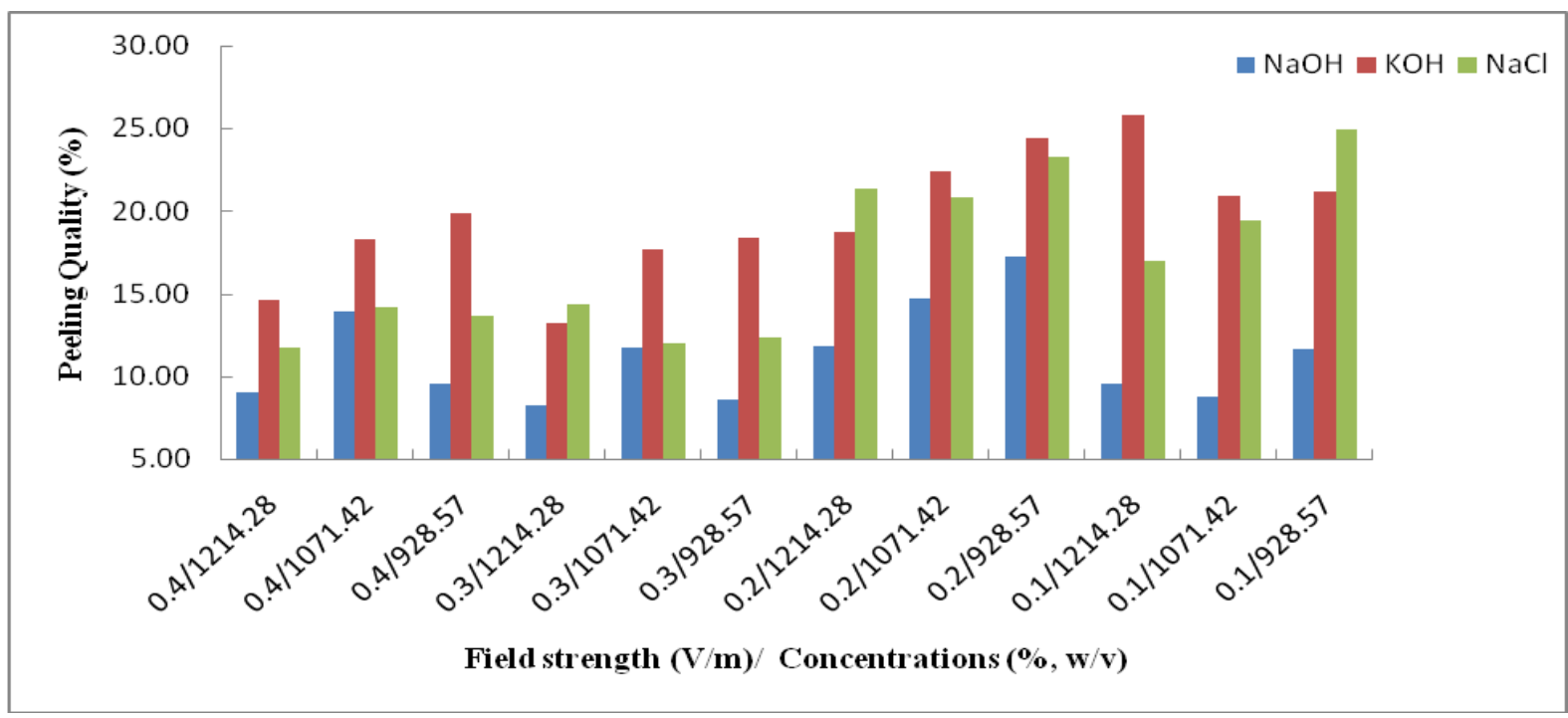

The higher and lower limit value of loss of peeling recorded under the conditions of $0.1 \%$ $\mathrm{KOH} / 1214.28 \mathrm{~V} / \mathrm{m}$ and $0.3 \% \mathrm{KOH} / 1214.28$ $\mathrm{V} / \mathrm{m}$ respectively. The temperature values were varied from $79{ }^{\circ} \mathrm{C}$ to $93.3{ }^{\circ} \mathrm{C}$ for $0.1 \% \mathrm{KOH} /$ $928.57 \mathrm{~V} / \mathrm{m}$ and $0.4 \% \mathrm{KOH} / 1214.28 \mathrm{~V} / \mathrm{m}$ respectively. The effect of ohmic heating on the ease of peeling of tomato under various conditions. The high peel score (4) for the ease of peeling was observed at $0.3 \% \mathrm{KOH}$ at $1214.28 \mathrm{~V} / \mathrm{m}$. The observed value of percentage of peeling and ease of peeling under various concentrations of $\mathrm{NaCl}$ which were ranged from $0.1 \%$ to $0.4 \%$ showed in following graphs. Minimum value of percentage of peel (11.40) was recorded for $0.3 \% \mathrm{NaCl}$ at $1214.28 \mathrm{~V} / \mathrm{m}$ field strength while maximum value of percentage of peel (24.92) for $0.1 \% \mathrm{NaCl}$ at $928.57 \mathrm{~V} / \mathrm{m}$ field strength were observed. The minimum and maximum temperature values were for $78.0{ }^{\circ} \mathrm{C}$ to $93.7^{\circ} \mathrm{C}$ for solution $\mathrm{NaCl}$ concentration respectively. All the conditions regarding the ease of peeling score were ranged from lower 2 to higher of 5. Levels of 4 and above were regarded as an acceptable level for ease of peeling. The reported average ease of peeling scores for ohmic heating were $5,4,4,5,5,4,2,3,2,3,3,2$, ,respectively. The best result evaluated for the ease of peeling having score 4 and 5 were $0.4 \% \mathrm{NaCl} / 124.28 \mathrm{~V} / \mathrm{m}$, $0.4 \% \mathrm{NaCl} / 1071.42 \mathrm{~V} / \mathrm{m}, 0.3 \% \mathrm{NaCl} / 928.57$ $\mathrm{V} / \mathrm{m}, 0.3 \% \mathrm{NaCl} / 1214.28 \mathrm{~V} / \mathrm{m}, 0.3 \% \mathrm{NaCl} /$ $1071.42 \mathrm{~V} / \mathrm{m}, \quad 0.3 \% \quad \mathrm{NaCl} / 928.57 \mathrm{~V} / \mathrm{m}$ respectively. The score of ease of peeling of tomato where in the agreement of warden by $\mathrm{Li}$ et al., (2009) who has reported based on his research work. A score of 4 and 5 were regarded as an acceptable. As indicated in below figures that the percentage of peeling increased the field strength had major effect on percentage of peeling. Percentage of peeling could be decreased with decreasing the concentration of medium from $0.4 \%$ to $0.1 \%$.

The graphical representation of experimented data for various field strengths and concentrations showed that minimum loss of flesh occurred under $0.3 \% \mathrm{NaOH}$ at $1214.28 \mathrm{~V} / \mathrm{m}$ condition. Higher the concentrations of $\mathrm{NaOH}$ and field strengths both are effective and obtained an acceptable quality of peeling. However the peeling loss ranged from 8.27 to $25.79 \%$ from experimented samples. The finding of present study is with the agreement of Garcia and Barrett (2006) who's reported that $7-10 \%$ was the desirable range of peeling losses for hand-peeled tomatoes. This range was closely represented by 
ohmic heating peeling under $\mathrm{NaOH}$ concentration (Figure 8).

Once the temperature rise to the $60^{\circ} \mathrm{C}$ wax melting occurred permitting allowing a pathway to electric current. This would tend to increase the rate of various cell walls (epicarp, pericarp, hemicelluloses) breakdowns and in combination with electric current flow and thermal effects, would result in disruption of the skin. When the lye- salt concentration of the medium increases, the heat generation in the medium would be quicker due to higher electrical conductivity. The wax melting would accelerate, resulting in low process time. Although cracking occurred faster at the higher electric field strengths. In terms of time of cracking, the best conditions of ohmic treatments were: $0.3 \% \mathrm{NaOH}$ at 1214.28 $\mathrm{V} / \mathrm{m}$ and $0.3 \% \mathrm{KOH}$ at $1214.28 \mathrm{~V} / \mathrm{m}$. These conditions showed the probable to be good for processing because they required a relatively short time (less than $60 \mathrm{~s}$, approximately). Moreover, the potential to preheat the media to $60^{\circ} \mathrm{C}$ with reusable media could further shorten the peeling time. The higher the electric field strength and lye-salt concentrations the shorter the time required for peel cracking. Ohmic tomato peeling treatments with $\mathrm{NaOH}(0.1,0.2$ 0.3 and $0.4 \%$ ) were better than those by ohmic heating with either $\mathrm{NaCl}$ or $\mathrm{KOH}$, in terms of time of cracking and quality of peeling

\section{References}

Cheryl, R., Yang, W., Renee G.S. and Feng. H. 2012. Conventional and alternative methods for tomato peeling. Journal of Food Engg., Rev, 4:1-15.

Doreo, M.L.J.S. 2009. The history of tomato. International Journal of Tropical Agriculture, 12: 193-225.
Eliot, S.C., Goullieux, A. and pain, J. P. 1991. Alication of firming effect of low temperature long time pre-cooking to ohmic heating of potatoes. Science des Aliments, 20(2): 265-280.

Fellow, P. 2000. Food Processing Technology. $2^{\text {nd }}$ edition. England, Woodhead publications limited: $373-377$.

Floros, J. D. and Chinnan, M. S. 1987. Diffusion phenomena during chemical $(\mathrm{NaOH})$ peeling of tomatoes. Journal of food science, 55(2), 552-553.

Garcia, E. and Barrett, D.M. 2005. Peel ability and yield of processing tomatoes by steam or lye. Journal of Food Processing and Preservation, 30:3-14.

Garcia, J.M., Ballesteros, J.M. and Albi, M.A. 1995. Effect of foliar applications of $\mathrm{CaCl}_{2}$ on tomato stored at different temperatures. Journal of Agricultural and Food Chemistry, 43: 9-12.

Kautkar, S. S., Pandey, J. P., Singh, A. and Kumar, A. 2016. Development of ohmic heating apparatus for extraction of rapeseed oil. International Journal for Innovative Research in Science and Technology, 29(11): 211-215.

Li-jun., Li-D., Tatsumi V., Liu-.Z., Chen, X. D. and Li-Te. 2009. Application of two-stage ohmic heating to tofu processing. Journal of Chemical Engineering and Processing, 46:486-490.

Went, L., Broholm, J., Cassiman, J. J., Craufurd, D., Falek, A., Farmer-Little, C. and Mol, M. 1994. Guidelines for the genetic growth requirement in tomato species. Journal of Medical Genetics, 31(7), 555-559

\section{How to cite this article:}

Sawant, S.R., J.P. Pandey, Anupama Singh and Om Prakash. 2018. Performance and Evaluation of Ohmic Heating Assisted Lye and Salt Concentration on Peeling Quality of Tomato. Int.J.Curr.Microbiol.App.Sci. 7(09): 3515-3524. doi: https://doi.org/10.20546/ijcmas.2018.709.436 